and suspected Lyme borreliosis. Neurology Sept 1997;49:817-824). (Reprints: Dr David Nadal, University Children's Hospital, Infectious Diseases Unit, Steinwiesstr. 75, CH-8032 Zurich, Switzerland).

COMMENT. Analysis of CSF for intrathecal specific antibodies to $B$. burgdorferi in children presenting with acute peripheral facial palsy may facilitate early diagnosis and prompt antibiotic treatment. In patients with lymphocytic pleocytosis but no intrathecal antibodies, detection of seroconversion by analysis of convalescent serum is important in diagnosis.

Neurologic signs and syndromes associated with Lyme disease in children are reviewed in three reports and commentaries in Progress in Pediatric Neurology III, PNB Publishers, 1997;pp484-5. In one series of 96 patients, facial palsy occurred in 14\%. Pseudotumor, reviewed in the following report, was diagnosed in $6 \%$ of cases of Lyme disease.

\title{
PSEUDOTUMOR CEREBRI
}

\section{INCIDENCE RATES OF PEDIATRIC PSEUDOTUMOR CEREBRI}

Twenty nine cases of pseudotumor cerebri were identified in a retrospective study of records of 205,765 children aged 2-15 years presenting between 1979 and 1994 at the IWK Grace Health Centre, Dalhousie University, Halifax, Canada. The annual incidence of pseudotumor for the total group was 0.9 per 100,000 children; in age group 2-11 years, the incidence was 0.7 , and for 12-15 years, 1.5. Females were affected nearly 3 times more frequently than males. The adolescent age group was affected twice as frequently as younger children.(Gordon N. Pediatric pseudotumor cerebri: descriptive epidemiology. Can I Neurol Sci Aug 1997;24:219-221). (Reprints: Dr Kevin Gordon, IWK-Grace Health Centre, 5850 University Ave, Box 3070, Halifax, Nova Scotia, Canada B3J 3G9).

COMMENT. The increasing incidence of pseudotumor cerebri in later childhood and adolescence (1.5 per 100,000$)$, noted in this study of patients admitted after 1978 , was also noteworthy in earlier reports. A review of the literature before 1960 showed that $84(37 \%)$ of 224 patients of all ages were in children and of these $75(90 \%)$ were between 5 and 15 years of age. (Millichap JG. Pediatrics Feb 1959;23:257). Antecendent otitis media was reported in 29\%, and mild head injury or infection other than otitis occurred in an equal proportion of the cases. The advent of antibiotics virtually abolished the cases of "otitic hydrocephalus," and explained the increase in "idiopathic" cases in later reports. (See Progress in Pediatric Neurology III, PNB Publ, 1997;pp431433, for articles on signs and symptoms, the MRI, and treatment of pseudotumor cerebri).

\section{TRAUMATIC DISORDERS}

\section{POST-TRAUMATIC OLFACTORY DYSFUNCTION}

The degree of olfactory function and damage to olfactory bulbs and tracts were quantitatively determined in 268 patients with head trauma (HT) presenting with complaints of olfactory disturbance at the University of Pennsylvania Smell and Taste Center, Philadelphia, PA. Anosmia occurred in 179 patients (67\%), microsmia (lessened sense of smell) in $20 \%$, and $12 \%$ had normal sense of smell. Olfactory test scores after head trauma were not related 